\title{
A monocultura de Eucalipto no município de Lima Duarte (MG): Educabilidades Insurgentes a partir da Educação do Campo
}

\author{
Eucalyptus monoculture in Lima Duarte (MG): insurgent \\ educabilities from field education
}

Michele Alice da Silva ${ }^{1}$

Angélica Cosenza ${ }^{2}$

1 Graduada em Ciências Biológicas pela Universidade Federal de Juiz de Fora (UFJF). Mestre em educação pelo Programa de Pós Graduação em Educação da UFJF. Doutoranda do Programa de Pós Graduação em Educação da UFJF. Integrante do Grupo de Estudos e Pesquisa em Educação Ambiental (GEA) da UFJF. Professora na Rede Estadual de Minas Gerais. Email micheleasbio@gmail.com/ORCID 0000-0002-2891-0167

2 Professora da Faculdade de Educação da Universidade Federal de Juiz de Fora. Doutora em Educação em Ciências e Saúde (2014) pelo Núcleo de Tecnologia Educacional para a Saúde da UFRJ. Professora e pesquisadora no Grupo de Pesquisa "Núcleo de Educação em Ciência, Matemática e Tecnologia" (NEC/UFJF). Docente no Programa de Pós-Graduação em Educação da Faculdade de Educação da UFJF .Email ar_cosenza@ hotmail.com/ORCID 0000-0001-5412-5894

Palavras-chave:

Educação Ambiental.

Educação do Campo.

Discurso. Justiça

Ambiental.
Keywords:

Environmental

Education. Field

Educaction. Discourse.
RESUMO: Diante de uma multiplicidade discursiva em torno da questão e educação ambiental, discutimos sentidos de educadores/as do campo sobre a problemática da monocultura de eucalipto na zona rural do município de Lima Duarte- MG, utilizando a Análise Crítica do Discurso (ACD) como referencial teórico-metodológico. O problema social que moveu essa investigação se relacionou com o modo como a escola (e seus sujeitos) comumente significa processos de problemas/conflitos/injustiças ambientais a partir de discursos desenvolvimentistas que circulam em seu ambiente, o que sinaliza uma fragilidade em processos educativos, que podem legitimar práticas que sustentam a permanência de sujeitos em situação de vulnerabilidade socioambiental. O estudo parte de um diálogo entre a Educação do Campo e a Educação Ambiental para a Justiça Ambiental, pelo fato de ambos os campos afirmarem processos educativos insurgentes contextualizados ao território, reconhecendo historicamente as inúmeras lutas travadas por sujeitos que vivenciam situações de degradação ambiental. Assim, frente às concepções hegemônicas que asseguram o contexto de assimetrias ambientais, como a expropriação territorial das populações rurais e dos povos e comunidades tradicionais, recorremos neste estudo às educabilidades que emergem nos contextos locais, a fim de anunciar pedagogias insurgentes na escola, que potencializem a construção de uma sociedade mais justa e igualitária. A partir das análises, destacamos a possibilidade de mudança discursiva dos sujeitos entrevistados no que se refere às significações sobre o ambiente e a educação, frente às concepções hegemônicas que asseguram o contexto de assimetrias ambientais locais.

ABSTRACT: Given the multiplicity of discourses around the environmental education issues, we discuss the senses of rural educators about the problem of eucalyptus monoculture in the rural area of Lima Duarte-MG, using Critical Discourse Analysis (ACD) as a theoretical-methodological reference. The social problem that moved this investigation was related to the way the school (and its subjects) commonly means processes of environmental problems / conflicts / injustices from developmental discourses that circulate in their environment, which indicates a fragility in educational processes, that can legitimize practices that 
support the permanence of subjects in situations of socioenvironmental vulnerability. This study starts from a dialogue between Rural Education and Environmental Education for Environmental Justice, because both fields claim insurgent educational processes contextualized to the territory, historically recognizing the numerous struggles waged by subjects who experience situations of environmental degradation. Thus, against the view of hegemonic conceptions that assure the context of environmental asymmetries, such as territorial expropriation of rural populations and traditional peoples and communities, we resort in this study to the educations that emerge in local contexts, in order to announce insurgent pedagogies in the school, which enhance the building of a fairer and more egalitarian society. From the analyzes, we highlight the possibility of discursive change of the interviewed subjects regarding the meanings about environment and education, facing the hegemonic conceptions that ensure the context of local environmental asymmetries.

\section{INTRODUÇÃO}

Diante de uma multiplicidade discursiva em torno da questão ambiental, buscamos neste artigo compreender sentidos sobre a monocultura do eucalipto em escolas do campo do município de Lima Duarte, MG, a fim de anunciar educabilidades que evidenciem outros saberes e potencializam a compreensão e o enfrentamento de processos de injustiças ambientais. A reflexão aqui proposta parte de uma dissertação de mestrado defendida no ano de 2018 no Programa de Pós Graduação em Educação da Faculdade de Educação da Universidade Federal de Juiz de Fora, que discutiu sentidos dos/as educadores/as sobre a problemática da monocultura de eucalipto no município de Lima Duarte- MG (SILVA, 2018), utilizando a Análise Crítica do Discurso (ACD) como referencial teórico-metodológico (FAIRCLOUGH, 2001).

Considerando que discursos hegemônicos circulam em regiões rurais e que estes informam um determinado modelo de desenvolvimento e progresso ao campo e ainda que, quando incorporados às práticas educativas, podem legitimar concepções e práticas que sustentam a permanência de sujeitos em situação de vulnerabilidade socioambiental, Silva (2018), na dissertação supramencionada, propôs reflexões em torno de um problema social que se relaciona ao modo como a escola significa processos de problemas/conflitos/injustiças ambientais.

Neste artigo, pretendemos afirmar o potencial de educabilidade de processos conflitivos, mobilizando vozes de sujeitos atingidos (as) diretamente pela monocultura do eucalipto em Minas Gerais. Escolha que busca evidenciar uma produção de sentidos contrahegemônica que, frequentemente, circula de modo restrito na sociedade, em especial, na educação. Nessa direção, tais sentidos constituem-se uma provocação que nos convoca aqui à importância de tais práticas educativas significarem as vivências ambientais agudas, assim como os modos de luta, de sujeitos atingidos (as) por processos de degradação socioambiental no campo. 
Ensino, Saúde e Ambiente - Número Especial, pp. 271-288, Junho. 2020

Tal compreensão se faz em diálogo com estudiosos/as do campo socioambiental, mais precisamente da Ecologia Política, como Enrique Leff (2006) Boaventura de Sousa Santos (2006), Caterine Walsh (2017), Aníbal Quijano (2005) e Enrique Dussel (1993, 2011) os/as quais buscam compreender o atual contexto de crise ambiental a partir de uma racionalidade que emerge dos modos de ser, dos processos de luta, dos povos afro, ameríndios, subalternizados, e que incorpora as dimensões social, cultural e histórica às discussões sobre a relação sociedade-ambiente. Para tanto, deslocam seus olhares para outras epistemologias, ditas "desde del sur", ou "decoloniais", as quais propõem uma descolonização do saber, uma justiça cognitiva, que criam diálogo com conceitos como a inter-culturalidade, com perceptivas feministas e com preocupações sobre questões locais. Assim, partindo dessas concepções, assumem que o sistema mundo hegemônico se estabelece a partir de uma lógica moderna-colonizadora-capitalista-patriarcal-heteronormativa, que hoje pousa com mais precisão sobre os territórios da América Latina, e faz destes, territórios (saberes) em sacrifício frente ao avanço do capital (ACSELRAD; MELLO, 2009; LEFF, 2018; SOUSA SANTOS, 2006).

Ao nos voltarmos para a realidade do campo brasileiro, nas últimas décadas, vivenciamos uma intensa restruturação nos modos de produção a partir do estabelecimento de práticas de uso e manejo da terra, como a silvicultura, que se afirmam sob um discurso de caráter desenvolvimentista, para suprir a crescente demanda por recursos naturais e diminuir a pressão sobre os mesmos. Tal mudança na dinâmica de apropriação e uso do território ${ }^{1}$ faz do Brasil um dos maiores produtores de florestas plantadas do mundo. Em sua maioria, florestas compostas por pinus e eucalipto, sendo Minas Gerais o estado que lidera o ranking de área plantada, segundo dados da Confederação de Agricultura e Pecuária (CNA) (IBÁ, 2017).

Nesse cenário, a chegada do eucalipto em Lima Duarte-MG e região veio acompanhada de discursos de desenvolvimento local e crescimento econômico para o município, tendo apoio do poder público que, diante de uma economia leiteira estagnada, incentivou a venda de terras e a incorporação do plantio nas propriedades. Entre os anos de 2005 e 2011, a dinâmica de plantio de eucalipto foi monitorada por Moura e Saidan (2014), com técnicas de Sensoriamento Remoto e Sistemas de Informação Geográfica (SIG). De acordo com os resultados, em 2005, o município apresentava uma área plantada total de aproximadamente 2,26 km² de eucalipto, o que corresponde a 226 ha. Em2011, a área passa à 22,4 $\mathrm{km}^{2}$ ou 2.240 ha de plantações, o que corresponde a um crescimento de

\footnotetext{
${ }^{1} \mathrm{O}$ conceito de território aqui referenciado tem por base a concepção proposta por Porto-Gonçalves (2012), que compreende o território como "uma categoria espessa que pressupõe um espaço geográfico que é apropriado e esse processo de apropriação -territorialização- enseja identidades -territorialidades- que estão inscritas em processos sendo, portanto, dinâmicas e mutáveis, materializando em cada momento uma determinada ordem, uma determinada configuração territorial, uma topologia social“" (PORTO-GONÇALVES, 2012. p. 230).
} 
Ensino, Saúde e Ambiente - Número Especial, pp. 271-288, Junho. 2020

aproximadamente $891 \%$ em relação ao ano de 2005 .

Essa mudança significativa no tamanho da área plantada evidencia uma das denúncias fundantes da Educação do Campo: o avanço sobre os territórios camponeses. Maciçamente práticas como a apropriação privada da natureza, monoculturas, transgênicos, uso de agrotóxicos, mecanização da produção, criação de animais em larga escala vem sendo inculcadas na população com o aval do governo e apoio da grande mídia, como os discursos vinculados ao slogan "O Agro é Pop",2, que fartamente circula, afirmando o agronegócio como peça chave do desenvolvimento do país.

Contrapondo a visão positiva em torno do agronegócio, reconhecemos que este modelo de expansão agrícola produz um quadro de desigualdade de bens e serviços socioambientais, sendo o Brasil um dos países com o maior número de conflitos no campo. Segundo Layrargues (2017) o atual cenário ambiental se faz a partir de uma desregulação ambiental pública que atravessa os poderes executivo, legislativo e judiciário, e atinge todos os âmbitos da vida social, ao promover práticas que levam a degradação ambiental, a alteração dos marcos regulatórios da legislação ambiental, perda de aparatos da gestão ambiental pública e violência simbólica/física, com assassinato de lideranças ambientalistas no campo. Neste ponto, destacamos o atual contexto brasileiro, em que se registrou um aumento significativo no número de queimadas, principalmente na região Amazônica e no centro-oeste, o qual provocou mobilizações nacionais e internacionais em defesa das florestas e dos povos originários. Segundo Costa e Loureiro (2019),

Os questionamentos a esta depredação do ambiente que adotaram as formas de luta "contra a contaminação", implicam uma experiência de devastação e luta localnacional que deram sustentação a uma compreensão dos efeitos devastadores do capitalismo sobre o ambiente em nível global. Esses fatores reiteram sua importância na intervenção dos movimentos sociais latino-americanos na detenção do processo de contaminação, mudanças climáticas e catástrofes ecológicas em curso (COSTA, LOUREIRO, 2019, p.688).

Partindo da premissa que a "conflitualidade é marca do desenvolvimento territorial no campo brasileiro" (FERNANDES, 2012, p.17) nos debruçamos sobre a dimensão discursiva de processos educativos que emergem dos problemas/conflitos/injustiças ambientais locais, a luz dos estudos críticos do discurso, na busca por evidenciar:

las estrategias, prácticas y metodologías-pedagogías que se entretejen con y se construyen en las luchas de resistencia, insurgencia, cimarronaje, afirmación, reexistencia, re-humanización y liberación (Walsh, 2013), como a las acciones sociales, políticas, epistémicas, artísticas, poéticas, performáticas, espirituales — todas pedagógicas - que empleamos para resquebrar y fisurar, para in-surgir y

\footnotetext{
${ }^{2}$ AGRO é tudo: conceito. Disponível em: $<$ https://www.youtube.com/watch?v=VENm5PbXhZ0\&index=9\&list=PL2rEFOezDBZzDoJC8pDkoDAlvQB9 X>. Acesso em: 20 maio. 2019.
} 
Desse modo, para compreender os sentidos e significados de sujeitos que vivenciam/experienciam situações de injustiças ambientais, utilizamos a Análise Crítica do Discurso (ACD), por se tratar de um modelo analítico que possibilita identificar problemas sociais materializados em textos orais ou escritos, sendo a existência de um problema social precedente a escolha da análise (CHOULIARRAKI; FAIRCLOUGH, 1999).

Na ACD, o discurso é concebido como uma forma de ação no mundo, portanto, não se refere apenas a uma prática de representação do mesmo, compreende os sentidos e significados atribuídos as nossas ações. É pelo discurso que os sujeitos constroem a sua realidade social, baseada nas condições histórico-sociais e nas relações de poder. Portanto, o discurso está presente na construção de identidades, de valores, de sistemas de conhecimento (epistemologias) e de relações sociais (FAIRCLOUGH, 1998).

Segundo Fairclough (2016, p. 22), “as transformações sociais na vida social contemporânea são extensivamente conduzidas pelo discurso, no sentido que é o discurso que muda primeiro", ao incorporarem ou serem incorporados por elementos que potencializam novos sentidos e significados. É na possibilidade de mudança do discurso que a luta hegemônica se instaura, por meio de processos ideológicos que mantêm a hegemonia em curso ou a deslocam (VIEIRA; RESENDE, 2016). Assim, a fim de compreender se, e em que nível, os sujeitos resistem a novos discursos, demos ênfase aos processos de mudança discursiva e dos hibridismos ${ }^{3}$. A nossa compreensão se faz no campo da educação, por reconhecermos esta como elemento de disputa no estabelecimento da hegemonia, devido a sua potencialidade de inculcar ou transformar concepções que afirmam ou negam determinado modelo societário.

No que se refere à realidade campesina, os discursos hegemônicos, a fim de manter o avanço do agronegócio, afirmam um projeto de educação baseado em ideais desenvolvimentistas, inculcando valores e práticas capitalistas. Em contrapartida, os povos do campo, articulados por meio de coletivos e movimentos sociais, lutam por um modelo de educação que reafirme suas identidades, e valorize seus saberes e fazeres, como a produção agrícola camponesa.

Diante dessa conjuntura, nos colocamos a pensar educabilidades insurgentes que problematizam o atual contexto de desigualdade socioambiental e potencializam o enfrentamento de injustiças ambientais, por compreendermos que:

\footnotetext{
3 Movimento de discursos, estilos e gêneros de uma prática para outra. Textos híbridos apresentam características de diferentes gêneros, estilos e discursos (VIEIRA; RESENDE, 2016). Assim, demonstram diferentes compreensões (e reações) de sujeitos e grupos sociais acerca dos problemas/conflitos e injustiças socioambientais.
} 


\begin{abstract}
Los gritos no son solo reacciones y expresiones de susto. Son también mecanismos, estrategias y acciones de lucha, rebeldía, resistencia, desobediencia, insurgencia, ruptura y transgresión ante la condición impuesta de silenciamiento, ante los intentos de silenciar y ante los silencios — impuestos y estratégicos - acumulados. Los gritos reúnen silencios y reclaman — se apoderan de nuevas - voces secuestradas (Garzón, 2014), subjetividades negadas, cuerpos, naturaleza y territorios violados $y$ despojados (WALSH, 2017).
\end{abstract}

Nesse sentido, para compreensão da problemática ambiental em questão propusemos um diálogo entre a Educação do Campo e a Educação Ambiental para a Justiça Ambiental, pelo fato de ambos os campos afirmarem processos educativos contextualizados ao território, reconhecendo historicamente as inúmeras lutas travadas por sujeitos que vivenciam situações de vulnerabilidade socioambiental. Assim, analisaremos abaixo alguns sentidos de atingidos/as pela monocultura de eucalipto na cidade mineira de Lima Duarte, MG, para em seguida, discutir suas implicações à educação para justiça ambiental e educação do campo.

\title{
DISCURSOS SOBRE A MONOCULTURA DE EUCALIPTO EM LIMA DUARTE- MG: EDUCABILIDADES EM DISPUTA
}

Segundo Fairclough (2001, p. 90) as diferentes concepções ideológicas orientam as práticas sociais, de forma a modificar ou manter as "identidades sociais" e a "posição de sujeitos". Dessa maneira, conforme referenciamos, os distintos discursos sobre a questão ambiental, nos possibilitam compreender as relações de forças que permeiam determinado problema social, ao evidenciar tensões, contradições e heterogeneidades existentes.

Para compreender as diferentes concepções que orientam os discursos sobre a prática da monocultura de eucalipto em Lima Duarte- MG, tomamos as comunidades com os maiores plantios (São Domingos da Bocaina, Lopes e Capoeirão), o ambiente escolar da única escola existente na região, bem como espaços políticos e institucionais como contexto social de produção discursiva. $\mathrm{Na}$ análise dos discursos, privilegiamos o léxico e a intertextualidade ${ }^{4}$ manifesta, dando ênfase na representação discursiva e nos aspectos ideológicos.

Segundo relatos de funcionários do Instituto Estadual de Florestas (IEF), os primeiros plantios de eucalipto no município começaram por volta de 2004, com investidas de compra de terras para reflorestamento, concomitante com o estabelecimento de uma empresa multinacional na região, cuja atividade principal é a produção de carvão vegetal. Desde então, houve uma reordenação do território, que acarretou mudanças estruturais nos aspectos sociais, econômicos e culturais locais, como enfatizado no discurso abaixo de um desses funcionários:

Teve impacto ambiental, social e econômico. Total... tirou o homem do campo (...). O homem do campo produzindo bem ou mal, estava lá. Tirando leite, tendo o que comer. Porém, com a

\footnotetext{
${ }^{4}$ Se refere a capacidade dos sujeitos de incorporar discursos com potencial de reafirmar, contestar ou reestruturar as estruturas discursivas política e ideologicamente estabelecidas (FAIRCLOUGH, 2001).
} 
chegada da empresa os moradores venderam suas terras. Alguns vieram para a cidade, ficaram desempregados. Ou se empregados, com subempregos. A parte econômica ficou para o município de Bom Jardim, porque a atividade industrial se instalou lá.

Impactos ambientais e sociais decorrentes da prática também foram relatados em conversa com moradores/as e educadores/as ${ }^{5}$ durante visitas às comunidades, sendo os mais citados: o intenso uso de agrotóxicos durante o período de plantio, que acarretou mortandade de pássaros na região e a diminuição de peixes em rios e córregos da região; o aumento de doenças respiratórias, em decorrência da poeira proveniente do intenso fluxo de caminhões; e uma mudança na dinâmica socioeconômica, com o estabelecimento de empregos esporádicos e a necessidade mão-de-obra especializada, pelo fato da produção ser praticamente toda mecanizada, conforme enfatizado na fala de uma moradora da região com o maior plantio.

\begin{abstract}
As comunidades que sofrem né?(....) Emprego gerou muito pouco, né? Mesmo porque na região aqui não tem ninguém preparado para isso, né? (...). Então muita gente, homens e mulheres trabalharam muito nesses plantios, que eu fiquei sabendo. E depois já teve quem trabalhou no arraste. Que aí tem uma máquina que derruba. Isso eu não conheço ninguém aqui da região que trabalha nessa máquina.
\end{abstract}

No discurso acima, a "comunidade" é apresentada como impactada por problemas resultantes do plantio de eucalipto, o que caracteriza a percepção da monocultura de eucalipto na região como um problema ambiental. Ao se referir à necessidade de mão-de-obra especializada, fica evidente uma mudança nas relações de trabalho, a qual implica diretamente no modo de vida local, potencializando processos de desigualdades socioambientais e situações de vulnerabilidade socioeconômica.

No que se relaciona a maneira como tais processos são hegemonicamente anunciados, Loureiro et al. (2009) advertem que os problemas ambientais, bem como possíveis soluções para os mesmos, são significados a partir de uma perspectiva puramente ecológica, no intuito de externalizar dos debates e discussões os efeitos socioambientais desiguais, como as mudanças estruturais no campo brasileiro. Para Fairclough (1989) quanto menos perceptíveis forem os processos ideológicos, mais efetiva a ideologia se faz, pelo fato dos processos serem mais susceptíveis a críticas. Por muito tempo os saberes e fazeres dos povos do campo vem sendo subalternizados, sendo suas identidades retratadas por caricaturas pejorativas, as quais apresentam o campo como um local inferior, lugar de sofrimento e atraso sociocultural, quando comparado à parcela urbana.

Assim, por reconhecermos que esses processos ideológicos também se situam nos ambientes escolares, buscamos evidenciar marcas de questões agudas/vivas ${ }^{6}$ contra

\footnotetext{
${ }^{5}$ A escolha dos entrevistados se deu através da observação participante. As entrevistas foram conduzidas sem perguntas rígidas, priorizando a voz dos sujeitos, e dando enfoque aos dados relevantes para investigação. Sob a autorização dos entrevistados/as, as entrevistas foram gravadas e, posteriormente, transcritas e analisadas.

${ }^{6}$ Para Simonneaux; Simonneaux, (2010) questões socialmente vivas (mencionadas também pela sigla SAQs) são
} 
Ensino, Saúde e Ambiente - Número Especial, pp. 271-288, Junho. 2020

hegemônicas nos discursos de professores/as e gestores/as escolares ${ }^{7}$, por possibilitarem outras significações sobre os problemas locais, dando ênfase aos hibridismos, que podem sinalizar marcas de resistência ou dominação nos discursos (COSENZA et al, 2014). Tais marcas podem ser percebidas no discurso abaixo da educadora Carla, em que a mesma fez uso de um metadiscurso ("Vou para a cidade, porque na cidade que está o futuro") para se referir a concepções hegemônicas, que afirmam o urbano como superior ao rural.

Eu acho que nós que trabalhamos no campo temos a obrigação de valorizar, fazer o aluno entender onde ele mora. Ele tem que valorizar o lugar dele. Porque senão fica naquela ilusão:

"Vou para a cidade, porque na cidade que está o futuro", né.

No metadiscurso o emissor do discurso dá ideia de um distanciamento de si, tendo parte do discurso advinda de discursos de outros/as produtores/as. Fairclough (2001) ao discutir o uso do metadiscurso, evidencia as implicações desse fenômeno às representações de identidade, uma vez que, ao incorporar outros discursos, o sujeito se relaciona com as estruturas que os formulam, como suas concepções textuais políticas e ideológicas.

Nessa perspectiva, ao refletir sobre o campo das teorias pedagógicas, Arroyo (2014) ressalta que os processos pedagógicos hegemônicos, vinculados ao pensamento moderno, têm contribuído para a subaletrnização de sujeitos e de suas pedagogias. Dessa maneira, fazendo referência ao pensamento de Santos e Menezes (2009), de que não existe justiça social global sem justiça cognitiva global, o autor ressalta a premência de afirmarmos outras epistemologias para enfrentamento de processos de exclusão, desigualdades e injustiças, que os povos da América Latina historicamente vêm sendo submetidos a partir da colonização.

La colonialidade es uno de los elementos constitutivos y específicos del patrón mundial de poder capitalista. Se funda en la imposición de una clasificación racial/énica de la problación del mundo como piedra anguar de dicho patrón de poder y opera en cada uno de los planos, ámbitos y dimensiones, materiales y subjetivas, de la existência social cotidiana y a escala societal. Se origina y mundializa a partir de America (QUIJANO, 2000, p. 342).

Em busca de processos educativos que potencializem transformações sociais, nos colocamos em movimento de desconstrução das concepções postas por pedagogias de dominação, que afirmam uma história única, apolítica, excluindo as culturas de resistência, como as culturas populares latino-americanas, as quais foram violentamente subordinadas aos saberes dos colonizadores, em meio às brechas, como nos coloca Walsh (2017):

Pongo mi energía, esfuerzo y atención en lo encarnado, situado y local, en las resquebraduras existentes —en proceso y por venir- que desafían, transgreden, interrumpen y desplazan el sistema dominante, en las fisuras de abajo donde se encuentran, se construyen y caminan formas de estar-hacer-ser-sentir-pensar-saber-

aquelas que apresentam as seguintes características: 1) são questões sociais que estimulam práticas sociais, pressupõe amplo debate, e podem constituir conflitos sociais, 2) instituem controvérsias entre paradigmas distintos mobilizados por sujeitos de diferentes campos disciplinares ou diferentes campos políticos, culturais, sociais de atuação, 3) são questões vivas no conhecimento a ser ensinado.

${ }^{7}$ Os nomes utilizados para a pesquisa são fictícios, preservando o anonimato dos/as entrevistados/as. 
vivir muy otras y en las posibilidades mismas de hacer agrietar. Me refiero tanto a las estrategias, prácticas y metodologías-pedagogías que se entretejen con y se constru- yen en las luchas de resistencia, insurgencia, cimarronaje, afirmación, reexistencia, re-humanización y liberación (Walsh, 2013), como a las acciones sociales, políticas, epistémicas, artísticas, poéticas, performáticas, espirituales todas pedagógicas - que empleamos para resquebrar y fisurar, para in-surgir y construir, así como para ensanchar y profundizar las grietas. Es a todo eso a que me refiero cuando hablo del espacio, lugar, incidencia y el hacer de las grietas decoloniales (WALSH, 2017, p. 14).

Nas últimas décadas, marcas dessas pedagogias de resistência estavam se fazendo mais perceptíveis no contexto educacional brasileiro, por meio do acesso e da participação nas tomadas de decisões de sujeitos que deram novos contornos aos debates educativos, e fizeram emergir outros saberes e outras pedagogias como: Educação do Campo, Educação Indígena, Educação Quilombola, Pedagogia da Terra, Agroecologia (ARROYO, 2013). Nessa direção, contrapondo à concepções hegemônicas, os/as trabalhadores/as do campo, em meio à luta pelo direito à terra afirmaram outros processos educativos para os povos do campo, baseados na diversidade e em seus modos de vida, como ressalta Caldart (2003):

Uma escola do campo não é, afinal, um tipo diferente de escola, mas sim é a escola reconhecendo e ajudando a fortalecer os povos do campo como sujeitos sociais, que também podem ajudar no processo de humanização do conjunto da sociedade, com suas lutas, sua história, seu trabalho, seus saberes, sua cultura, seu jeito. Também pelos desafios da sua relação com o conjunto da sociedade (CALDART, 2003, p. 66).

A conjuntura histórica da Educação do Campo é marcada por uma trajetória de luta e muita resistência até sua consolidação em 1997 com a realização do I Encontro Nacional de Educadoras e Educadores da Reforma Agrária, promovido pelo Movimento dos trabalhadores Rurais sem Terra (MST), com apoio da United Nations Educational, Scientific and Cultural Organization (Unesco), da United Nations International Children's Emergency Fund is a United Nations (UNICEF), da Conferência Nacional dos Bispos do Brasil (CNBB) e da Universidade de Brasília (UNB), em que foi apresentado um Manifesto das Educadoras e dos Educadores da Reforma Agrária ao povo brasileiro, em defesa da permanência e existência dos povos do campo.

No ano seguinte, em 1998, foi realizada a I Conferência Nacional por uma Educação Básica do Campo- Luziânia (GO) que consolidou a construção de políticas públicas de educação, nesse mesmo ano foi criado o Programa Nacional de Educação na Reforma Agrária (PRONERA). No ano de 2002, foi lançada as Diretrizes Educacionais para a Educação Básica nas Escolas do Campo (BRASIL, 2002). E em 2004, foi criada a Secretaria de Educação Continuada, Alfabetização e Diversidade (SECAD/MEC), hoje extinta, configurando o período em que a Educação do Campo teve maior reconhecimento por parte do Estado. A fim de reafirmar tais políticas nacionais, o Estado de Minas Gerais, em 2015, lançou as Diretrizes para a Educação Básica das Escolas do Campo. Atualmente, na 
Ensino, Saúde e Ambiente - Número Especial, pp. 271-288, Junho. 2020

contramão desse cenário de conquistas, o Estado brasileiro vivencia um desmonte nas políticas educacionais, por meio de decretos e reformas oficializados de forma autoritária e antidemocrática, os quais impactam diretamente os processos educativos dos povos do campo, bem como em seus modos de vida.

Diante desse contexto, os povos do campo, empreendem lutas em prol da afirmação do território, a partir da compreensão do papel da escola na constituição deste:

Imagina se não tivesse a escola na comunidade? Era bem capaz de a comunidade estar com menos habitantes ainda. Entendeu? Porque a vida que a escola leva para a comunidade mantém algumas pessoas ainda na vila (...). Então essa relação da comunidade com a escola e da escola com a comunidade é muito interessante. (...) Quer dizer é o contato, é a relação.

Nesse trecho, o educador Renato, dá evidência a importância da escola para a comunidade, ao pressupor o aumento do êxodo rural caso a escola não existisse. Se voltarmos o olhar para o contexto brasileiro, historicamente, o campo foi se tornando um local "sem sujeitos", ou de sujeitos "em passagem", devido às mudanças estruturais nos modos de produção e nas ofertas de serviços públicos quanto comparados as zonas urbanas. Para Fairclough (2001), as identidades dos sujeitos se configuram em meio a processos ideológicos que buscam a estruturação das relações de poder. Ao agir discursivamente, evidenciamos gêneros, discursos e estilos distintos que levam a constituição, reprodução, contestação e reestruturação das identidades.

Nesse sentido, destacamos a defesa do movimento por uma educação do campo em demarcar discursivamente seus processos identitários em todo processo educativo, seja nas práticas educativas ou na constituição da denominação "do" campo, a qual busca caracterizar as educabilidades pertencentes aos sujeitos do campo. Portanto, uma escola do campo se constrói a partir dos sujeitos que a compõem, mesmo sendo realocada para uma área urbana.

Assim, acreditamos que ao afirmamos processos educativos que emergem dos contextos, a partir de saberes e fazeres locais, potencializamos a desconstrução de processos outros que reforçam quadros de desigualdade, exclusão e injustiça.

\section{DIÁlOGOS ENTRE A EDUCAÇÃO AMBIENTAL E A EDUCAÇÃO DO CAMPO: EM BUSCA DE OUTRAS EDUCABILIDADES POSSÍVEIS}

A perspectiva de Educação Ambiental (EA) da qual tomamos parte se debruça sobre o potencial de educabilidade das questões ambientais locais, por possibilitar o reconhecimento e compreensão de processos de problemas/ conflitos/ injustiças ambientais, e potencializar um possível enfrentamento dos mesmos. Tal perspectiva tem como base o movimento por Justiça Ambiental (JA), o qual concebe que os danos ambientais são distribuídos de forma desproporcional entre os diferentes grupos sociais, por isso, reconhecemos a importância do 
engajamento social dos educadores na luta pela transformação da sociedade (COSENZA et al., 2014; COSENZA et al, 2018). Uma EA que se faz crítica na sua defesa do ambiente assume o enfrentamento de violações de direitos decorrentes de injustiças sociais, como a luta pelo território rural que se configura na defesa da identidade cultural e dos modos de existência dos povos do campo. Tal concepção parte de uma perspectiva educativa coerente com o contexto, que potencializa o enfrentamento das ideologias capitalistas e coloca em xeque temáticas como a luta de classes no embate político contra hegemônico.

Nesse sentido, nessa seção buscamos identificar nos discursos dos/as educadores/as de uma escola localizada na região com maior plantio de eucalipto do município sentidos sobre a problemática ambiental local. No discurso abaixo a educadora Carla faz referência a uma das maneiras com que a questão do eucalipto adentra a escola:

Tipo assim, a gente tem aqui o problema do eucalipto, né. Eles às vezes comentam: "Famílias que venderam terreno para essas grandes empresas de eucalipto e foram para a cidade" né. Comparam casa na cidade e foram embora.

Em seu discurso, a educadora evidencia um processo de reestruturação do campo a partir da instalação de grandes empreendimentos, que levam a desterritorialização do campesinato.

Para Guimarães (2012), as ações pouco críticas de educadores/as podem ser relacionadas a não compreensão de noções em formação, como a concepção de desenvolvimento, de modernização, bem como das relações de força em torno das mesmas, em decorrência de uma racionalidade que compreende o mundo e suas relações de forma reduzida, fragmentada, individualista, cientificista, mercadológica, que invisibiliza os aspectos sociais desiguais. Nessa perspectiva, sentidos acerca da realidade local, que denotam uma compreensão limitada sobre processos motivadores de problemas socioambientais locais, podem contribuir para que os mesmos não sejam reconhecidos como injustiças socioambientais. Em sentido oposto, usando do metadiscurso em referência aos dizeres dos/as educandos/as (Eles às vezes comentam), a educadora Carla evidencia um processo recorrente ao campo ao mencionar as implicações sociais locais, como venda de terras e o êxodo rural, denotando conhecimento de tal realidade e a produção de educabilidade a partir dela.

Segundo Fairclough (2006), mudanças sociais estão entrelaçadas à mudanças das práticas socais, as quais, por sua vez, à mudanças dos discursos, sendo estes a mudarem primeiro. Dessa maneira, devido à natureza dialética "externa" dos discursos, é possível ocorrer processos de recontextualização discursiva, resultantes de relações de poder, dominação, luta e resistência, os quais podem ser revelados nos processos de hibridismo interdiscursivos (FAIRCLOUGH, 2006, 2001).

Como já referenciamos, a partir de uma conjuntura histórica, os projetos societários 
para o campo brasileiro sempre estiveram sob o domínio de discursos hegemônicos, marcados por uma valorização da dimensão econômica, que se afirma com base nas demandas e leis do mercado. No entanto, como o "desenvolvimento" no/do campo não se faz de forma igualitária, ficando a produção e a renda sob o domínio de monopólios do Estado e empresas privadas, destacamos a possibilidade de mudança discursiva e das práticas sociais dos sujeitos, por meio da visão dos/as educadores/as sobre a relação escola-comunidade e as mudanças no território, uma vez que o reconhecimento da escola para Escola do Campo motivou inquietações com potencial de ressignificar o processo educativo, estas evidenciadas, por exemplo, no discurso do educador Renato:

Acho que aí nós precisamos trabalhar um pouco melhor isso, conversar mais sobre isso, para nós
vermos se, de fato, esse nome- escola do campo- faça alguma coisa pelo campo. E voltando ao
que eu disse, ao que eu estava dizendo, que não permita, por ser escola do campo, às vezes, esse
exxodo fora do horário, sem motivo e sem razão. (...). Então nós precisamos dedicar um pouco
mais de tempo para transformar a nossa escola em uma "Escola de Campo".

No segmento acima, o ator social está representado pelo sujeito "nós", o qual indica que o educador se coloca como agente da ação, que seria uma reflexão/ação coletiva sobre a Educação do campo, e seus princípios. O discurso anuncia possíveis mudanças a partir da nova intitulação "Escola do Campo", como o estabelecimento de práticas educativas que contribuam para a permanência dos sujeitos no campo.

Com base neste movimento de possibilidade de mudança discursiva, buscamos, nos próximos segmentos, dar ênfase a dois discursos que revelam o modo como os/as educadores/as relacionam o currículo e as práticas educativas ao contexto local, na busca por afirmar processos educativos outros, que assumam a politicidade ${ }^{8}$ da educação (FREIRE, 2001).

E a gente tá tentando fazer com que eles vejam o valor, com que eles valorizem mesmo o que vem da horta, o que vem do quintal, as frutas, né. Os legumes, as hortaliças. Então a gente tá, "vamos fazer agora uma feirinha”. Eles vão trazer os produtos que eles têm em casa, qualquer coisa até mesmo os biscoitos, broas que eles fazem.

Resolvemos editar um livro falando um pouco da ruralidade do município. Exatamente para mostrar as pessoas que ela existe, que ela é importante, que ela é bonita, que ela é fotografada, que lá tem gente. A gente tem que ter um cuidado, um olhar mais atencioso para essa ruralidade.

No primeiro discurso, com o uso de pressuposição, que faz referência a proposições anteriormente consideradas ( $E$ a gente tá tentando), a educadora Carla aponta para o potencial educativo de uma horta escolar, no que se relaciona a valorização dos saberes presentes no

\footnotetext{
${ }^{8}$ Segundo Paulo Freire não tem como um educador progressista entender a educação como algo neutro. É preciso que o processo educativo esteja aliado com a questão histórica sendo capaz de potencializar no sujeito a compreensão da realidade natural e histórica a qual está inserido. Nesse sentido, assumir a politicidade da educação seria partir de uma prática educativo-política que visa despertar no oprimido uma consciência crítica por reconhecer que estamos inseridos em uma sociedade classista (FREIRE, 2001).
} 
Ensino, Saúde e Ambiente - Número Especial, pp. 271-288, Junho. 2020

contexto local, sendo citados alguns desafios enfrentados para permanência da mesma, como a participação dos/as professores/as e o período de férias, os quais levaram a paralisação das atividades na horta. No segundo segmento, de encontro às concepções hegemônicas que negam territórios campesinos, o educador Renato cita a produção de um livro pelos/as educadores/as e educandos/as da escola com objetivo de retratar a contexto local, valorizando e afirmando seus saberes e fazeres. O livro, que foi editado em 2016, apresenta a realidade de diferentes comunidades rurais de Lima Duarte-MG a partir dos olhares dos/as moradores/as, por meio de fotografias, narrativas, desenhos e poemas (ALMEIDA, 2016).

Segundo Camacho (2017), a disputa pela a hegemonia do campo brasileiro fez com que diversos discursos fossem cooptados pelo Estado e pela iniciativa privada, como exemplo da Educação do Campo, e, por isso, escolas intituladas "do campo", não necessariamente, assumem pedagogias comprometidas com existência/permanência dos povos do campo. Nesse sentido, reconhecermos que as práticas educativas (enunciadas por hortas, livros), apresentadas nos segmentos acima, se fazem insurgentes, ao afirmarem saberes e fazeres locais, pertencentes ao território campesino, tomadas como tema geradores e não como, no dizer de Layrargues, atividades-fim. Tais atividades, para o autor, contribuem para que não se perca a possibilidade de compreensão da complexa inter-relação dos componentes políticoeconômicos e socioculturais da questão ambiental (LAYRARGUES, 1999).

Nessa perspectiva, em busca de uma ressignificação do processo educativo, enfatizamos a potencialidade de práticas educativas que se pretendem reflexivas e críticas na estruturação e constituição de comunidades que vivenciam assimetrias socioambientais. Nosso intuito é destacar a possibilidade mudança discursiva na constituição do processo educativo, a fim de anunciar a possibilidade de construirmos outro currículo na prática, que para além de dar visibilidade às injustiças socioambientais nos contextos escolares, contribuem para enfrentamento das mesmas. Assim, para finalizar a análise dos sentidos dos/as educadores/as, destacamos o segmento abaixo em que a educadora sinaliza um caminho possível:

Eu acho assim, que a gente deveria mesmo, enquanto escola, deveria estar trabalhando isso. E assim, mostrando, mostrando esse lado oculto para eles, de tudo. Que existe, sabe? Para eles crescerem com o espírito crítico, sabe? Porque eles são muito só da gente receber. Eu vejo isso nos nossos alunos: só recebem. O que eles recebem, eles aceitam e passam pra frente, e tal né. Como se a gente aqui fosse assim. Soubesse de tudo do que a gente fala, tudo que a gente passa para eles, tudo certinho né. Entendeu? Eu vejo eles com pouca maldade. Pouco críticos.

Ao qualificar os/as educandos/as como "pouco críticos", e sinalizar caminhos para se alcançar processos educativos com um viés crítico, "mostrando esse lado oculto para eles", o discurso da educadora Paula nos remete aos dizeres de Caldart (2004), de que a práxis $^{9}$ é o

\footnotetext{
${ }^{9}$ Conforme afirmado por Loureiro $(2004$, p. 130) práxis é “a atividade concreta pela qual o sujeito se afirma no
} 
Ensino, Saúde e Ambiente - Número Especial, pp. 271-288, Junho. 2020

grande desafio dos sujeitos que constroem a Educação do Campo, por demandar uma ampla reflexão e coerência com o contexto local na constituição/afirmação das práticas educativas.

Desse modo, ao direcionar o nosso olhar para os sentidos de educadores/as sobre questões ambientais locais em sua relação com a educação foi possível compreender tensões e disputas em torno da produção e reprodução de sentidos sobre o ambiente e a constituição de outras pedagogias.

\section{CONSIDERAÇÕES FINAIS:}

(...) o futuro com que sonhamos não é inexorável. Temos de fazê-lo, de produzi-lo, ou não virá da forma como mais ou menos queríamos. É bem verdade que temos de fazê-lo não arbitrariamente, mas com os materiais, com o concreto de que dispomos e mais com o projeto, como o sonho por que lutamos (FREIRE, 2016, p. 141).

É com a Pedagogia da Esperança de Freire que tecemos nossas últimas palavras. No intuito de contrapor pedagogias de dominação, as quais contribuem para a invisibilização e o silenciamento de sujeitos que, no campo, vivenciam situações de vulnerabilidade socioambiental, buscamos refletir e anunciar aqui pedagogias insurgentes que emergem em contextos locais de enfrentamento do capital.

A partir de nossas análises, destacamos a possibilidade de mudança discursiva dos sujeitos no que se refere às significações sobre o ambiente e a educação, frente à concepções hegemônicas que asseguram o contexto de assimetrias ambientais no campo. Para Fairclough (2006), os processos que levam a mudanças sociais estão entrelaçados às mudanças das práticas sociais, que por sua vez, derivam de mudanças nos discursos. Desse modo, a recontextualização discursiva torna-se possível na experiência humana, em função da natureza dialética "externa" dos discursos que são susceptíveis às relações de poder, dominação, luta e resistência, com destaque aos processos de hibridização discursiva, em que diferentes visões/concepções são incorporadas pelos sujeitos, permitindo aos processos ideológicos atuar (FAIRCLOUGH, 2001).

Nesse sentido, é inegável que a historicidade do campo brasileiro, marcada por uma lógica capitalista que, em busca de manter o sistema-mundo moderno-colonizador-capitalistapatriarcal-heteronormativo, inculcou ideais nos territórios campesinos, fazendo com que os sentidos sobre o ambiente fossem hegemonicamente interpretados (COSTA, LOUREIRO, 2019). Como o desenvolvimento hegemônico se dá de forma a causar desigualdades, acarretando uma expropriação territorial das populações rurais, dos povos e comunidades tradicionais, reconhecer e valorizar saberes e fazeres desses sujeitos é caminho para anunciar 
Ensino, Saúde e Ambiente - Número Especial, pp. 271-288, Junho. 2020

pedagogias de resistência e luta pelo território.

Desse modo, diante dos discursos hegemônicos, que dominam os espaços públicos e midiáticos, reproduzindo as demandas do mercado, como os produzidos pelo braço pedagógico da Associação Brasileira do Agronegócio (ABAG), os quais difundem seus “interesses e valorizam a imagem do agronegócio no país” (LAMOSA; LOUREIRO, 2014. p.534), e invisibilizam sujeitos e processos de injustiças ambientais, nos valemos de discursos docentes que resistem e se anunciam nos mais diversos espaços, como no ambiente escolar, e potencializam uma práxis pedagógica com compromisso social.

Entendemos com Fairclough (2003) que relações assimétricas de poder são instáveis, passíveis de mudança e superação. E é nessa direção que compreendemos que a hibridização discursiva, de alguma forma, afeta o poder: o discurso original é recontextualizado, toma parte em algo diferente, e assim é capturado em trajetórias de mudança discursiva imprevistas por aqueles que ora marcaram seu lugar de origem. A colonização por um discurso é sempre uma apropriação desse discurso, a qual pode afrouxar o controle do colonizador. Esta é a base para a luta ideológica no discurso.

Para Fairclough, as origens e as motivações imediatas da mudança no evento discursivo repousam na problematização das convenções. Intérpretes tentam resolver aquilo que ele denomina de "dilemas", sendo inovadores ou criativos ou adaptando-se as convenções existentes de novas maneiras e, assim, contribuindo para a mudança discursiva. Acreditamos que a hibridização de discursos constitui na escola uma travessia em possibilidades de transformação da prática docente.

Neste ponto, destacamos a importância da análise de discurso nas pesquisas sobre as ações e transformações do capitalismo, por se interessar em compreender como os efeitos ideológicos do discurso neoliberal são produzidos ou deslocados e quais são suas implicações em práticas sociais específicas, como a educação. No que se relaciona a questão ambiental, a ACD nos possibilita compreender a disputa ideológica pela hegemonia no campo da EA, ao revelar processos de naturalização, ocultação ou manipulação de certos discursos, possibilitando a deslegitimação de certos discursos e o fortalecimento de outros, como o que se fazem contra-hegemônicos (FREIRE et al., 2016).

$\mathrm{Na}$ contramão do modelo educacional hegemônico, afirmamos processos educativos em consonância com os contextos locais, corroborando com a luta de sujeitos que protagonizam outros processos educacionais, como a Educação do Campo, que na sua origem se fez pelo direito aos Trabalhadores e Trabalhadoras Sem Terra, e, hoje, articula o direito a todos os Povos do Campo (indígenas, quilombolas, ribeirinhos, etc).

Diante do atual contexto de perda de direitos, decorrente de um desmonte ambiental e educacional, assumimos a luta por uma educação ambiental que realmente seja comprometida 
Ensino, Saúde e Ambiente - Número Especial, pp. 271-288, Junho. 2020

com os sujeitos em situação de vulnerabilidade socioambiental como uma forma de contribuir no processo de construção de sociedades socioambientalmente justas.

Nessa perspectiva, cabe a nós, educadores e educadoras comprometidos/as, política e pedagogicamente, com um projeto de educação transformador, indagar qual o modelo de educação estamos afirmando? Qual o papel da escola nessas lutas? Que escola dará conta de pedagogias insurgentes? São perguntas no caminho de experienciar uma pedagogia dialógica, crítica, participativa, corajosa, aberta, no dizer Caterine Walsh (2017), aos gritos, às gretas e às sementes, que nos mostram que não somos poucos/as e que mundos, modos e práticas outros existem e seguem em germinação e potência de vida.

\section{REFERÊNCIAS BIBLIOGRÁFICAS}

ACSELRAD, H.; MELLO, C.C. A. O que é Justiça Ambiental. Rio de Janeiro, RJ: Garamond, 2009.

ALMEIDA, A. P. E.; Silva Arthur (Org.). Minha Terra, minhas memórias. 1. ed. Juiz de Fora: Editora Juiz Forana, 2016. v. 2200. 96p.

ARROYO, M. Outros sujeitos, outras pedagogias. 2. ed. Petrópolis, RJ: Vozes, 2014.

. Currículo, Território em Disputa. Petrópolis, RJ: Vozes, 2013.

BRANDÃO, C. R. O que é Educação? 24. Ed. São Paulo: Brasiliense, 1989. (Coleção Primeiros Passos).

BRASIL. Conselho Nacional de Educação. Câmara de Educação Básica. Resolução nº 1, de 03 de abril de 2002. Institui Diretrizes Operacionais para a Educação Básica nas Escolas do Campo. Brasília, DF: MEC, 2002. Disponível em: < http://portal.mec.gov.br/index.php?option=com_docman\&view=download\&alias=13800rceb001-02-pdf\&category_slug=agosto-2013-pdf\&Itemid=30192>. Acesso em: 10 jun. 2019.

BULLARD, R. Enfrentando o Racismo Ambiental no Século XXI. In: ACSELRAD, H; HERCULANO, S.; PÁDUA, J. A. Justiça Ambiental e Cidadania. Rio de Janeiro: RelumeDumará: Fundação Ford, p. 41-68, 2004

CALDART, R. S. Pedagogia do movimento sem terra. São Paulo: Expressão Popular, 2004. p.60-81, jan./jun. 2003.

A Escola do Campo em Movimento. Currículo sem Fronteiras, v.3, n.1,

CAMACHO, R.S. A Educação do Campo em disputa: resistência versus subalternidade ao capital. Educação e Sociedade. Campinas, v. 38, n. 140, p.649-670, jul./set. 2017.

CHOUliARAKI, L., FAIRCLOUGH, N. Discourse in Late Modernity. Edinburgh University Press, Edinburgh, 1999.

COSENZA, A.; SILVA, M. A. ARAÚJO, J. C.; PEREIRA, C. C. R. a Construção Discursiva de um Conflito Ambiental na Escola: Estratégia Discursiva ou Cooptação Ideológica na Escola? . In: VILELA, M. L.; MENDES, R. R. L; PINHÃ̃, F. L; RIOS, N. T. Aqui também tem Currículo! Saberes em diálogo no ensino de Biologia, 1.ed. - Curitiba: Editora Prismas, 2018.162p. 
Ensino, Saúde e Ambiente - Número Especial, pp. 271-288, Junho. 2020

COSENZA, A., FREIRE, L.M., ESPINET, M., MARTINS, I. Relações entre justiça ambiental, ensino de ciências e cidadania em construções discursivas docentes. Revista Brasileira de Pesquisa em Educação em Ciências. Belo Horizonte, v.14, n. 2, p. 89-98, 2014.

COSTA, C.A. LOUREIRO, C.F. A questão ambiental a partir dos sem direitos: uma leitura em Enrique Dussel. E-Curriculum. p. 673-698, 2019.

DUSSEL, E. La cuestión ecológica en Marx. In: MARTINEZ, Leonardo Montenegro (ed.). Cultura y Naturaleza. 1 ed. Bogotá: Jardín Botánico de Bogotá, José Celestino Mutis, 2011. p. $227-238$.

1492 o encobrimento do outro: a origem do mito da modernidade. Conferências de Frankfurt/ Enrique Dussel tradução Jaime A. Clasen - Petrópolis, RJ: Vozes, 1993.

FAIRCLOUGH, N. Semiose, mediação e ideologia: uma visão dialética. Parágrafo. São Paulo, v. 4, n. 1, p. 17-27, jan./jun. 2016.

Discurso e Mudança Social. Brasília: Editora da Universidade de Brasília,

2001

FREIRE, P. Pedagogia da esperança: um reencontro com a pedagogia do oprimido. 23. ed. São Paulo/Rio de Janeiro: Paz e Terra, 2016. de Nossa Época. Volume 23).

Política e educação: ensaios 5. Ed. São Paulo, Cortez, 2001. (Coleção Questões

Educação como prática da liberdade. Rio de Janeiro: Paz e Terra, 1967.

GUIMARÃES, M. A formação de educadores ambientais. 8 ed. Campinas, SP:

Papirus,2012.

IBÁ - INDÚSTRIA BRASILEIRA DE ÁRVORES. Relatório Anual - 2017. Brasília, DF, 2017. Disponível em: http://iba.org/images/shared/Biblioteca/IBA_RelatorioAnual2017.pdf>. Acesso em: 10/02/2018.

LAMOSA, R. LOUREIRO, C.F. B. Agronegócio e Educação Ambiental: uma análise crítica. Ensaio: aval. pol. públ. Educ., Rio de Janeiro, v.22, n. 83, p. 533-554, abr./jun. 2014.

LAYRARGUES, P. P, Anti ecologismo no Brasil: reflexões ecopolíticas sobre o modelo do desenvolvimentismo-extrativista-predatório e a desregulação ambiental pública. In: OLIVEIRA, M.M.D., MENDES, M., HANSEL, C.M., DAMIANI, S. (Org). Cidadania, Meio Ambiente e Sustentabilidade. Caxias do Sul: EDUCS. p.325-356. 2017. Disponível em: file:///C:/Users/STI/Desktop/Layrargues-AntiEcologismonoBrasil.pdf. Acesso em: 27 abr. 2019.

LAYRARGUES, P, P. A resolução de problemas ambientais locais deve ser um tema gerador ou a atividade-fim da educação ambiental? In: REIGOTA, Marcos. Verde cotidiano: o meio ambiente em discussão. Rio de Janeiro (RJ): DP\&A Editora, 1999. p. 131-148.

LEFF, E. A aposta pela vida: imaginação sociológica e imaginários sociais nos territórios ambientais do Sul. Editora Vozes Limitada, 2018.

Racionalidade Ambiental: a reapropriação social da natureza. Rio de Janeiro: Civilização Brasileira, 2006.

LOUREIRO, C.F.B. Trajetórias e fundamentos da educação ambiental. São Paulo: Cortez, 2004. 
LOUREIRO, C. F.; B.; BARBOSA, G. L.; ZBOROWSKI, M. B. Os vários "ecologismos dos pobres" e as relações de dominação no campo ambiental. In: LOUREIRO, C.F.B;

LAYRARGUES, P. P.; CASTRO, R. S. (Org.). Repensar a educação ambiental: um olhar crítico. São Paulo: Cortez, 2009. p. 81- 118.

MOURA, A. B. A.P.; ZAIDAN, R. T. Dinâmica evolutiva da distribuição espacial de plantio de eucalipto no município de Lima Duarte, MG- 2005-2011. Revista de Geografia, Juiz de Fora, v. 4, no 1, p, 01-06, 2014.

NETO, R.M.; ZAIDAN, R.T.; JUNIOR, W.N.; MOURA, A.B.A.P. Estrutura e dinâmica da paisagem no município de Lima Duarte (MG): uma abordagem geoecológica. Caminhos de Geografia. Uberlândia, v. 15, n. 52. p.134-150, dez. 2014.

PORTO-GONÇALVES, C. W. Da geografia às geo-grafias: um mundo em busca de novas territorialidades. Em Ceceña, A. E. e Sader, E. (orgs.), La guerra infinita: hegemonía y terror mundial. Buenos Aires: Clacso, 2012.

QUIJANO, Aníbal. Colonialidad del Poder y Clasificacion Social. Special Issue: Festchrift for Immanuel Wallerstein - Part I. Jornal of world-systems research. v.6, n.2, 2000, p. 342386

SÁNCHEZ. C. Stortti, M. a. Prefácio dos autores. Educação Ambiental desde Eı Sur / Anne Kassiadou... [et al.]. 1. ed. Atualizada. Macaé: Editora NUPEM, 2018.

SANTOS, B.S; MENEZES, M.P. (Orgs.). Epistemologias do Sul. São Paulo: Cortez, 2009.

SILVA, M.A. Sentidos sobre a monocultura de eucalipto no município de Lima Duarte (MG): educabilidades possíveis a partir da educação ambiental e da educação do campo. Dissertação (mestrado acadêmico). Universidade Federal de Juiz de Fora. Faculdade de Educação.

Programa de Pós educação em Educação, 2018.

SILVA JÚNIOR, R. A. M. O Sistema ideológico do agronegócio: o poder do discurso e o discurso pelo poder. 2015. 202 f. Tese (Doutorado em Geografia). Faculdade de Ciências e Tecnologia, Universidade Estadual Paulista, Presidente Prudente, 2015.

SIMONNEAUX, L; SIMONNEAUX, J. Students' socio-scientific reasoning on controversies from the viewpoint of education for sustainable development, In: Cult. Stud. Of Sci Educ . Vol. 4, p. 657-687, 2010.

SOUSA SANTOS, B. Conocer desde el Sur: Para una cultura política emancipatória. Peru: 2006.

THOMPSON, J. B. Ideologia e cultura moderna: teoria social crítica na era dos meios de comunicação de massa. Petrópolis, RJ: Vozes, 1995.

WALSH, Catherine (Ed.). Pedagogías decoloniales: prácticas insurgentes de resistir, (re)existir y (re)vivir. Tomo II. Quito, Ecuador: Ediciones Abya-Yala, 2017. 